\title{
A Comparative Study of Histogram Equalization Techniques and Adaptive Gamma Correction for Color Image Contrast Enhancement
}

\author{
Chhaya Gautam \\ Dept. of Electronics and Communication Engg. \\ Technocrats Institute of Technology \\ Bhopal, India
}

\author{
Neeraj Tiwari \\ Dept. of Electronics and Communication Engg. \\ Technocrats Institute of Technology \\ Bhopal, India
}

\begin{abstract}
The most noteworthy conclusion of image processing is a contrast enhancement. The most regular system for histogram equalization is utilized for retouching contrast within digital images. Histogram equalization is so advantageous and useful for image contrast enhancement method. Nonetheless, the traditional histogram equalization methods normally conclusion in surpassing complexity upgrades which variable the non-common look and noticeable curio of the handled picture. In this paper exhibits an alternate new manifestation of histogram for picture contrast enhancement. A few systems are this station is the measuring used to grant the data histogram. Global Histogram Equalization GHE utilizes the force dissemination of the whole image. Shine safeguarding Bi -Histogram Equalization BBHE utilizes the mean force is adjusted image autonomously. Double Sub -Image Histogram Equalization DSIHE utilizes the average force is adjusted image autonomously. Least Mean Brightness Error Bi -HE MMBEBHE utilizes the partition of image based on edge level, prepares the most modest Absolute Mean Brightness Error AMBE. Recursive Mean -Separate Histogram Equalization RMSHE is more different advance system for histogram adjustment. Extent Limited Bi-Histogram Equalization RLBHE jelly the initially brilliance well in order to separate the threshold that minimizes the intra - class difference. Review same that everybody these methodologies are more straightforward and valuable for image contrast
\end{abstract}

\section{General Terms}

Image Enhancement, Histogram Equalization, Bi-Histogram Equalization, Adaptive Gamma Correction.

\section{Keywords}

Color Image Contrast Enhancement, Histogram Equalization, Brightness Preserving Enhancement, Range Limit, Histogram Partition.

\section{INTRODUCTION}

Image enhancement could be process including changing the pixels' power of the information Image, with the goal that the yield Image should subjectively look better [1]. The objective of Image enhancement is to enhance the interpretability of data held in Image for human viewer, or to prepare a "superior" info for distinctive mechanized Image handling framework. As a rule, the improvement procedures for darkened pictures might be extensively isolated into two classes: direct enhancement methods [2]-[4] and indirect enhancement methods [5]-[7]. In direct enhancement methods, the picture differentiation might be specifically characterized by a particular difference term [2]-[4]. Then again, the greater part of these measurements can't all the while gauge the differentiation of straightforward and complex examples in pictures which hold both.

An extremely prevalent method for Image enhancement is histogram equalization (HE) [8]. Histogram equalization is wide utilized for contrast upgrade throughout a kind of requisition attributable to its simple perform and viability. One downside of the histogram adjustment may be found on the exact truth that brilliance of a Image could be changed when histogram leveling that is particularly attributable to the smoothing property of the histogram equalization [2]. Global Histogram Equalization (GHE) is one in all the chief typically utilized routes for Image contrast upgrade in light of the fact that as an aftereffect of its high power and effortlessness. It's accomplished by normalizing the force conveyance exploitation its aggregate circulation works in place that the outcome Image could have an uniform dissemination of power [3]. On the other hand, since GHE is generally exploitation the force circulation of the complete pict Image should experiences real burdens like over upgrade, build in the commotion level, lost in subtle element and washed-out impact in some very nearly homogeneous range [1].

In the late years, a few scientists proposed various accommodating calculations to intention these issues concerned in GHE method. These a few ways are Brightness protecting Bi- Histogram Equalization (BBHE) [2], Equal Area Dualistic Sub-Image Histogram Equalization (DSIHE) [4] and Minimum Mean Brightness Error Bi-Histogram equalization (MMBEBHE) [5], and so on. BBHE isolates the info image histogram into two parts backed the mean of the information image thus every half is equivalent severally. It's been dissected each numerically and through a test that this framework is competent to save the first brightness to specific degrees. The DSIHE technique is similar to BBHE with the exception of that it divides the histogram backed the average worth. MMBEBHE is an alternate amplification of BBHE that has most astounding brilliance protection by exploitation the limit level, which may yield minimum distinction between information and yield mean. In spite of the fact that these ways will perform sensible complexity improvement, they conjointly cause a great deal of irritating aspect impacts figuring on the variety of ash level dispersion inside the histogram. Conjointly RMSHE (Recursive Mean- Separate Histogram Equalization) [9] and RSIHE (Recursive SubImage Histogram Equalization) [10] are recursive calculations 
of BBHE and DSIHE. These two recursive ways have enhanced outcomes investigation with past ways. The mean brilliance of the yield was much the same as that of the info in RMSHE and RSIHE. However, the leveling outcome was diminished. Another bi-histogram balance algorithm $\mathrm{m}$ is alluded to as Extent Limited Bi-Histogram Equalization (RLBHE) [8]. This philosophy takes both contrast change and brilliance conservation under thought. To acknowledge higher contrast enhancement8 and keep away from over improvement, Otsu's procedure [7] is utilized to perform histogram threshold. Then we tend to limit the range of the equal image to ensure that the mean output brightness can be almost equal to the mean input brightness [8].

\section{IMAGE CONTRAST \\ ENHANCEMENT METHODS}

\subsection{Global Histogram Equalization (GHE)}

Assume that $X=\{X(i, j)\}$ is for a digital image, where $X(i, j)$ represents the gray level of the pixel at $(i, j)$ position. If $n$ is total number of pixels in image and $\mathrm{L}$ is pixel intensity levels that are $\left\{\mathrm{X}_{0}, \mathrm{X}_{1}, \mathrm{X}_{2} \ldots \ldots \mathrm{X}_{\mathrm{L}-1}\right\}$. Let $\mathrm{n}_{\mathrm{k}}$ represents the total number of pixels with grey level of $X_{k}$ in the image, then the probability density of $X_{K}$ will be

$$
\mathrm{p}\left(\mathrm{X}_{\mathrm{k}}\right)=\frac{\mathrm{n}_{\mathrm{k}}}{\mathrm{n}}, \mathrm{k}=0,1, \ldots \ldots \ldots, \mathrm{L}-1
$$

The Probability Density Function (PDF) shows the relationship between $\mathrm{p}\left(\mathrm{X}_{\mathrm{k}}\right)$ and $\mathrm{X}_{\mathrm{k}}$ and The Cumulative Distribution Function (CDF) can be defined in termed as PDF as:

$$
\mathrm{C}\left(\mathrm{X}_{\mathrm{k}}\right)=\sum_{\mathrm{j}=0}^{\mathrm{L}-1} \mathrm{p}\left(\mathrm{X}_{\mathrm{j}}\right)=\sum_{\mathrm{j}=0}^{\mathrm{L}-1} \frac{\mathrm{n}_{\mathrm{k}}}{\mathrm{n}}
$$

Where $\mathrm{k}=0,1, \ldots \ldots \ldots, \mathrm{L}-1$, and it is obvious that $\mathrm{c}\left(\mathrm{X}_{\mathrm{L}-1}\right)=1$ and transform function $\mathrm{f}(\mathrm{x})$ in terms of $\mathrm{CDF}$ can be expressed as:

$$
\mathrm{f}(\mathrm{x})=\mathrm{X}_{0}+\left(\mathrm{X}_{\mathrm{L}-1}-\mathrm{X}_{0}\right) \mathrm{c}(\mathrm{x})
$$

GHE yields output images $\mathrm{Y}=\{\mathrm{Y}(\mathrm{i}, \mathrm{j})\}$, it can be represents as:

$$
\mathrm{Y}=\mathrm{f}(\mathrm{x})=\{\mathrm{f}(\mathrm{X}(\mathrm{i}, \mathrm{j}) \forall \mathrm{X}(\mathrm{i}, \mathrm{j}) \in \mathrm{X}\}
$$

where $\mathrm{X}$ is a continuous random variable.

$$
\mathrm{p}(\mathrm{y})=\frac{1}{\mathrm{X}_{\mathrm{L}-1}-\mathrm{X}_{0}}
$$

Thus, the mean intensity level of the output image's HE is

$$
E(Y)=\int_{X_{0}}^{X_{L-1}} y p(y) d y
$$

So that output mean of the HE does not conceder mean intensity label of the original image [8].

\subsection{Dualistic Sub-Image Histogram Equalization (DSIHE)}

Taking after the indistinguishable essential ideas utilized by the BBHE system of deteriorating the original image into two sub - images thus level the histograms of the sub- images exclusively, [4] proposed the therefore known as equivalent zone dualistic sub- images HE (DSIHE) procedure. Instead of breaking down the image underpinned on its mean grey level, the DSIHE procedure decays the images pointing at the amplification of the Shannon's entropy [6] of the output image of deteriorating the original picture into two sub-images along

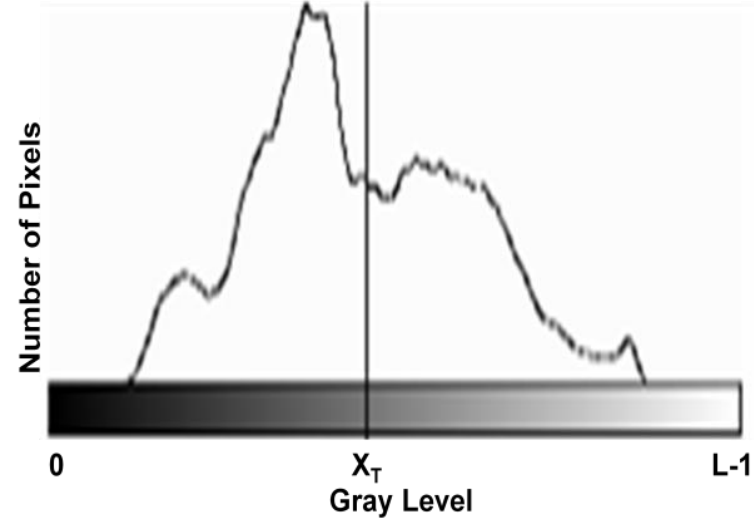

Fig 1: Bi-histogram Equalization

these lines balance the histograms of the sub-images exclusively. For such objective, the data image is deteriorated into two sub-images, being one dull and one Bright, regarding the equivalent region property (i.e., the sub-images has the same measure of pixels) [4], its demonstrated that the brightness of the output image O made by the DSIHE method is that the normal of the equivalent territory level of the image I and thusly the middle grey level of the image, i.e., L/ 2. The creators of [4] claim that the brightness of the output image produced by the DSIHE strategy does not exhibit a huge movement in reference to the brightness of the info image, especially for the extensive region of the image with the indistinguishable light grey levels (spoke to by little regions in histograms with pleasant amassing of ash levels), e.g., image with little questions joining with decent darker or brighter foundations.

\subsection{Minimum Mean Brightness Error Bi- Histogram Equalization (MMBEBHE)}

As of now emulating the major principle of the BBHE and DSIHE routines for part a Image then applying the HE strategy to level the resulting sub-images severally proposed the minimum mean brightness error Bi-HE (MMBEBHE) strategy [5]. The most peculiarity between the BBHE and DSIHE ways and additionally the MMBEBHE one is that the last hunt down an edge level $1 \mathrm{t}$ that parts the Image I into two sub-Images $\mathrm{I}\left[0, \mathrm{l}_{\mathrm{t}}\right]$ and $\mathrm{I}\left[\mathrm{l}_{\mathrm{t}}+1, \mathrm{~L}-1\right]$, specified the minimum brightness distinctness between the information Image and likewise the output image is attained, though the past ways make singularly the input image to perform the disintegration. When the information image is deteriorated by the edge Levell $_{t}$, each of the two sub-images I $\left[0, l_{t}\right]$ and I $\left[l_{t}+1, L-1\right]$ has its histogram equivalent by the established HE technique, creating the output image. Presumptions and controls for discovering the threshold level $\mathrm{l}_{\mathrm{t}}$ in $\mathrm{O}(\mathrm{L})$ time complexity was made in [6].Such procedure grants us to get the brightness $\mathrm{l}_{\mathrm{m}}(\mathrm{O}[\mathrm{O}, 1] \cup \mathrm{O}[1+1, \mathrm{~L}-1])$ of the output image while not creating the output picture for each hopeful edge level 1 , and its point is to give a strategy fitting to genuinetime provision.

\subsection{Recursive Mean-Separate He Method (RMSHE)}

Review that the enlargements of the HE strategy portrayed so far in this segment were portrayed by decomposing the original image into two new sub-images. Be that as it may, an expanded form of the BBHE strategy named recursive mean separate HE (RM SHE), proposes the accompanying. Rather than deteriorating the image just once, the RMSHE technique proposes to perform image deterioration recursively, up to a 
scale $r$, producing $2 \mathrm{r}$ sub-images. After, every one of these sub-images. $\mathrm{I}^{\mathrm{r}}\left[\mathrm{l}_{\mathrm{f}}, \mathrm{l}_{\mathrm{s}}\right]$ is freely upgraded utilizing the CHE system. Note that when $r=0$ (no sub-images. are produced) what's more $r=1$, the RMSHE technique is proportionate to the CHE and BBHE systems, separately. In [5], they mathematically demonstrated that the brightness of the output image is better saved as $r$ increments. Note that, computationally talking, this system shows an impediment: the amount of disintegrated sub-histograms is a power of two.

\subsection{Range Limited Bi-Histogram Equalization (RLBHE)}

RLBHE is formally plot by the ensuing systems:

- Selecting a legitimate threshold for histogram detachment

- Affirm the higher and hence the lower bounds for histogram adjustment

- $\quad$ Adjust each part severally

From the example distinguishment point of view, the best edge should make the least complex execution to independent the target class from the foundation class. This execution is portrayed by intra-class change. Otsu's procedure [7] is utilized to naturally perform histogram structure based for the most part image edge. The calculation expect that the image to be threshold holds two classes of pixels (e.g., closer view also foundation) then ascertains the optimum edge dividing those two classes so that their intra-class change is least.

The safeguarding of the mean brightness is of levels of popularity in customer characteristic rationality. In spite of the fact that the edge threshold got by Otsu's method will successfully separate the items from the foundation, the mean brightness may not be strictly strained. Further measures ought to be taken to deal with the root image brightness ideally. The aftereffect of (RLBHE) [8] indicates that the arranged calculation rule has saved the brightness well and gives the natural enhancement in most separated of the image [10]. Fig. 1 shows the Bi-histogram method in which the histogram with range from 0 to $\mathrm{L}-1$ is subdivided into two parts, with separating intensity $\mathrm{X}_{\mathrm{T}}$. This separation produces two sub histograms. The first histogram has the range of 0 to $\mathrm{X}_{\mathrm{T}}$, while the second histogram has the range of $\mathrm{X}_{\mathrm{T}+1}$ to $\mathrm{L}$ 1 [11].

\subsection{Adaptive Gamma Correction (AGC)}

Gamma correction strategies make up a group of general HE strategies got basically by utilizing a changing versatile parameter $\gamma$ [9]. The straightforward type of the transformbased gamma correction (TGC) is inferred by Equation (7)

$$
\mathrm{T}(\mathrm{l})=\mathrm{l}_{\max }\left(\frac{\mathrm{l}}{\mathrm{l}_{\max }}\right)^{2}
$$

Where lmax is the maximum intensity level of image. The intensity 1 of every pixel in the data image is changed as T (1) after performing Eq. (1). Not surprisingly, the gamma bends represented with $\gamma>1$ have precisely the inverse impact as those created with $\gamma<1$. It is vital to note that gamma amendment lessens at the character bend when $\gamma=1$.

Then again, when the difference is straightforwardly altered by gamma amendment, diverse pictures will show the same changes in power as an aftereffect of the altered parameter. Luckily, the probability density of every power level in an advanced picture might be figured to take care of this issue.
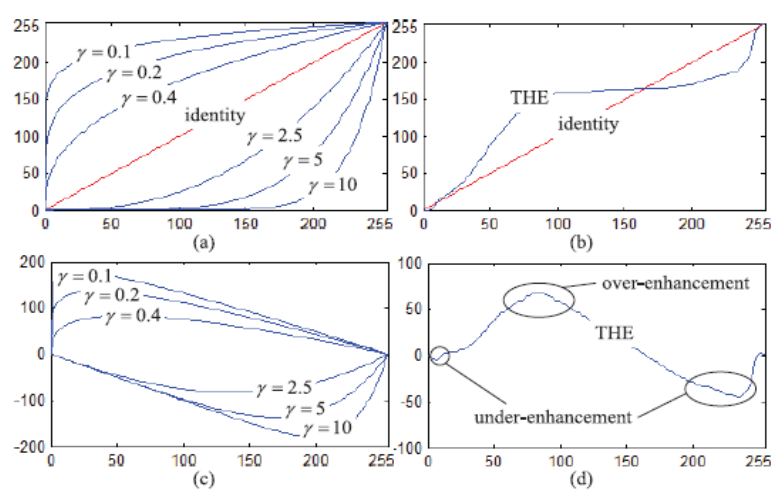

Fig 2: Transformation curves illustrated by (a) gamma correction and (b) THE methods, with their corresponding intensity level modifications shown in (c) and (d)

Table 1.Comparisons Between Deferent Histograms Equalization Methods

\begin{tabular}{|c|c|c|c|}
\hline \multirow[b]{2}{*}{ Name } & \multicolumn{3}{|c|}{ Characteristics } \\
\hline & Method & $\begin{array}{c}\text { Contrast } \\
\text { Enhancement }\end{array}$ & AMBE \\
\hline GHE & $\begin{array}{c}\text { Calculate } \\
\text { cumulative } \\
\text { distribution } \\
\text { function }\end{array}$ & Good & $\begin{array}{l}\text { Absolute } \\
\text { mean } \\
\text { Brightness } \\
\text { Error is } \\
\text { Minimum } \\
\text { up to some } \\
\text { extent }\end{array}$ \\
\hline ВРВНE & $\begin{array}{c}\text { Calculate } \\
\text { Mean of } \\
\text { image. }\end{array}$ & $\begin{array}{l}\text { Better than } \\
\text { GHE }\end{array}$ & $\begin{array}{l}\text { Minimum } \\
\text { than GHE }\end{array}$ \\
\hline DSIBHE & $\begin{array}{l}\text { Calculate } \\
\text { median of } \\
\text { image. }\end{array}$ & $\begin{array}{l}\text { Much better } \\
\text { than BBHE }\end{array}$ & $\begin{array}{l}\text { Minimum } \\
\text { than BBHE }\end{array}$ \\
\hline MMBEBHE & $\begin{array}{c}\text { Calculate } \\
\text { minimum } \\
\text { brightness } \\
\text { difference } \\
\text { between } \\
\text { input image } \\
\text { and output } \\
\text { image }\end{array}$ & $\begin{array}{l}\text { Much Better } \\
\text { than DSIBHE }\end{array}$ & $\begin{array}{l}\text { Minimum } \\
\text { than } \\
\text { DSIBHE }\end{array}$ \\
\hline RLBHE & $\begin{array}{l}\text { Apply } \\
\text { threshold } \\
\text { selection } \\
\text { method } \\
\text { (Otsu's } \\
\text { method) }\end{array}$ & $\begin{array}{c}\text { Improved } \\
\text { Contrast than } \\
\text { other }\end{array}$ & $\begin{array}{c}\text { Minimum } \\
\text { than } \\
\text { MMBEBH } \\
\text { E }\end{array}$ \\
\hline AGC & $\begin{array}{l}\text { Progressive } \\
\text { ly increase } \\
\text { the low } \\
\text { intensity } \\
\text { and avoid } \\
\text { the } \\
\text { significant } \\
\text { decrement } \\
\text { of the high } \\
\text { intensity. }\end{array}$ & $\begin{array}{c}\text { More } \\
\text { Improved than } \\
\text { RLBHE }\end{array}$ & $\begin{array}{l}\text { Minimum } \\
\text { than } \\
\text { RLBHE }\end{array}$ \\
\hline $\begin{array}{c}\text { RLBHE with } \\
\text { AGC } \\
\text { (Proposed) }\end{array}$ & $\begin{array}{c}\text { Hybridizati } \\
\text { on of } \\
\text { RLBHE } \\
\text { and AGC }\end{array}$ & $\begin{array}{c}\text { Will be more } \\
\text { improved then } \\
\text { AGC }\end{array}$ & $\begin{array}{l}\text { Will be } \\
\text { extremely } \\
\text { minimum }\end{array}$ \\
\hline
\end{tabular}


The adaptive gamma correction (AGC) is formulated as follows:

$$
\mathrm{T}(\mathrm{l})=\mathrm{l}_{\max }\left(\frac{\mathrm{l}}{\mathrm{l}_{\max }}\right)^{\gamma}=\mathrm{l}_{\max }\left(\frac{\mathrm{l}}{\mathrm{l}_{\max }}\right)^{1-\operatorname{cdf}(\mathrm{l})}
$$

The AGC method can progressively increase the low intensity and avoid the significant decrement of the high intensity.

$$
\begin{array}{lll}
\text { Where } & \operatorname{cdf}(\mathrm{l})=\sum_{\mathrm{k}=0}^{\mathrm{l}} \operatorname{pdf}(\mathrm{k}) \\
\text { And } & \operatorname{pdf}(\mathrm{l})=\mathrm{n}_{\mathrm{l}} /(\mathrm{MN})
\end{array}
$$

Where $n_{l}$ the number of pixels that have intensity 1 and $M N$ is the total number of pixels in the image.

Different weaknesses exist as to the TGC and THE methods. Fig.2(c) and (d) indicate the altered qualities of every intensity by utilizing the comparing bends showed as a part of Fig. 2(a) and (b). The $x$-direction is the info intensity and the $y$ direction is the decrement or addition of every intensity level. As indicated in Fig.2(c), unvaried alteration is generated by the utilization of the TGC method with a predefined parameter. Then again, THE method utilizes the property of the histogram to upgrade the intensity differentiate; this unseemly adjustment is indicated in Fig. 2(d). Overenhancement and under-enhancement are in reality real tests because of the unnatural changes in CDF. Case in point, three regions are surrounded in Fig. 2(d) that call attention to these unfavorable impacts: some low intensity levels are still diminished, moderate intensity levels are fundamentally expanded, and high intensity levels are essentially diminished.

\section{EXPECTED RESULTS AND PERFORMANCES OF PROPOSED METHOD}

Table I shows the comparison between the different histogram equalization methods which have been reviewed in this paper, also shows the expected results of proposed method which is the hybridization of RLBHE and AGC for contrast enhancement of low contrasted images. This implies that this proposed method with hybridization of RLBHE and AGC may result enhanced image as similar to original image with extremely minimum Absolute Mean Brightness Error (AMBE).

\section{CONCLUSION}

We have introduced the correlation of four Histogram Equalization strategies. The relative investigation of Histogram Equalization based techniques indicates that the substance that need higher brightness safeguarding and not holed well by HE, BBHE and DSIHE are suitably expanded by RMSHE. MMBEBHE is that the expansion of BBHE strategy that gives more brightness safeguarding. In spite of the fact that these techniques will do sensible differentiation improvement, they conjointly cause a parcel of irritating symptoms looking on the variety of ash level appropriation inside the histogram. RLBHE is development strategy for MMBEBHE. Table I shows the comparison between different differentiation improvement strategies. In future work we will work with Hybridization of Range Limited Bi-Histogram and Adaptive Gama Correction methods for color image contrast enhancement. This will transform undoubtedly better come about contrast with alternate procedures

\section{ACKNOWLEDGMENTS}

The authors would like to express their sincere thanks to Dr. Shivendra Singh, Head of the Department of Electronics and Communication and all faculty members of the department for their kind support.

\section{REFERENCES}

[1] Gonzalez, R. C. and Woods, R. E. 2002 Digital Image Processing. 2nd edition. Prentice Hall.

[2] Kim, Y. T. 1997 Contrast enhancement using brightness preserving Bi-Histogram equalization. IEEE Trans. Consumer Electronics. Vol. 43. No. 1. pp. 1-8.

[3] Umbaugh, S.E. 1998 Computer Vision and Image Processing. Prentice Hall. Ne Jersey. pp. 209.

[4] Wan, Y., Chen, Q. and Zhang, B. M. 1998 Image enhancement based on equal area dualistic sub-image histogram equalization method. IEEE Trans. Consum. Electron. 45, pp. 68-75.

[5] Chen, S. D. and Ramli, A. R. 2003 Minimum mean brightness error bi-histogram equalization in contrast enhancement. IEEE Trans. Consum. Electron. 49. pp. 1310-1319.

[6] Chen, S. D. and Ramli, A. R. 2003 Contrast enhancement using recursive mean separate histogram equalization for scalable brightness preservation. IEEE Trans. Consum. Electron. 49. pp. 1301-1309.

[7] Otsu, N. 1979 A threshold selection method from graylevel histograms. IEEE Trans Syst. Man Cybern. 9. pp. 62-66.

[8] Zuo, C., Chen, Q. and Sui, X. 2013 Range limited bihistogram equalization for image contrast enhancement Optik 124. pp. 425-431.

[9] Huang, S. C., Cheng, F.C. and Chiu, Y. S. 2013 Efficient Contrast Enhancement Using Adaptive Gamma Correction With Weighting Distribution IEEE Transactions on Image Processing. Vol. 22. No. 3. pp. 1032-1042.

[10] Shannon, C. 1948 A mathematical theory of communication. Bell Syst. Tech. J. Vol. 27. pp. 379-423. 